\title{
CAST STRUCTURE AND MECHANICAL PROPERTIES OF FINE GRAINED SUPERALLOY K4169 BY ADDITION OF REFINERS
}

\author{
Lin Liu ${ }^{1}$, Taiwen Huang ${ }^{1}$, Yuhua Xiong ${ }^{2}$, Aimin Yang ${ }^{3}$, Zhilong Zhao ${ }^{1}$, Rong Zhang ${ }^{1}$, and Jinshan $\mathrm{Li}^{1}$ \\ ${ }^{1}$ State Key Laboratory of Solidification Processing, Northwestern Polytechnical University, Xi'an 710072, P.R. of China \\ ${ }^{2}$ Beijing General Research Institute for Non-Ferrous Metals, Beijing 100088, P.R. of China \\ ${ }^{3}$ Department of Mechanical Engineering, Xi'an Petroleum Institute, Xi'an 710065, P. R. of China
}

Keywords: superalloy, grain refinement, microstructure, tensile properties, LCF, grain size

\begin{abstract}
Grain size and microstructural features of cast superalloy K4169 were investigated under various melting and casting conditions together with the addition of grain refiners. It is found that lowering the pouring temperature and adding refiners to the melt before pouring can lead to grain refinement of $\gamma$ matrix and improve the proportion of equiaxed grains. At a conventional pouring temperature of $1400{ }^{\circ} \mathrm{C}$, the average size of equiaxed grains could be refined to the order of ASTM $3.2(0.17 \mathrm{~mm})$, the proportion of equiaxed grains at the transverse cross-section could be improved from $56 \%$ to $99 \%$ with addition of a trace intermetallic compound into the melt. The results also indicate that the length of primary dendrite is shortened with the addition of refiners, but the secondary dendrite arm spacing keeps almost unchanged. Meanwhile, the microsegregation of main elements such as $\mathrm{Fe}, \mathrm{Cr}, \mathrm{Nb}$, Mo and $\mathrm{Ti}$ is alleviated with the decrease in grain size, and the grains have transformed from dendrite to granulation in fine-grained castings. The amount of microporosity in samples with the addition of refiners can be greatly reduced. The mechanisms of grain refinement and increase in equiaxed grain proportion were proposed.
\end{abstract}

Tensile properties at room temperature and at $700^{\circ} \mathrm{C}$ were tested. The rupture strength, yield strength, elongation and reduction of area for refined grains are all more superior to those of coarse ones. Whereas the elongation and reduction of area of fine grained samples decrease at $700^{\circ} \mathrm{C}$. Low cycle fatigue (LCF) properties of refined grain samples at room temperature are improved significantly. In addition, the degree of dispersion of LCF data of fined grain samples is diminished.

\section{Introduction}

The growing demands of advanced gas turbine engine technologies have required the development of high strength heat resistance materials. Various approaches have included directionally solidified alloys and eutectic superalloy, powder metallurgy, oxide dispersion strengthening and processing improvement to keep pace with the increasing temperature [1].

On the other hand, the operating temperature of turbine wheels of aircraft engines and industrial turbine engines is relatively low. For example, a rotor is customarily divided into three general areas, the hub, the rim and the blades. In the hub section, the operating temperature is approximately $700^{\circ} \mathrm{C}$ [2] which is typically below the creep range. Whereas stresses from centrifugal loads are high. High tensile strength and good low cycle fatigue
(LCF) resistance are primarily required. In this range, a uniform and fine grain size is desired to increase fatigue strengths and resistance to crack growth.

Since 1970's, developments were made for replacing to forged turbine wheels which have been plagued with large grains in the central hub areas, a location that is seldom adequately worked [3]. Alternatively, the optimum grain configuration can be obtained with investment casting. Whereas the predominant feature of conventional investment cast alloys is microstructural coarseness or non-uniformity of grain size. Therefore, to obtain a fine and uniform grain turbine wheels and other engine parts has been concerned by investment casters.

\section{A literature review of grain refinement of superalloys}

Grain Refinement Methods and their Application to Superalloys

Refinement of cast structure requires that nucleation occurs at a large number of sites and that extensive growth of crystals be avoided. It follows that grain refinement necessitates both ease of nucleation and inhibition of the continued growth of crystallites in the melts. The existing knowledge of grain size control can be divided in three basic ways [3, 4]: mechanically, chemically or thermally. That is agitation of the melt during the freezing, nucleation promoting and growth hindering additions, or rapid cooling.

In the early 1980 's, the first generation of fine-grain casting technique, named Grainex was developed by Howmet Turbine Component Corporation [5, 6]. In this process, castings are agitated during solidification to shear dendrites and initiate multiple nucleation sites, which subsequently leads to an uniform refined grain size, ranging from ASTM M9- M 13 (1.6- $0.4 \mathrm{~mm}$ ), close to ASTM $0(0.36 \mathrm{~mm})$.

Since 1984, Howmet introduced second generation of fine grain casting techniques $[5,7$, and 8]. This process is referred to as Microcast-X and offers the potential for producing integrally cast rotor components with a grain size in the ASTM 3 - 5 range ( 125 - $65 \mu \mathrm{m})$. In comparison with Grainex castings which exhibit a dendritic structure, the Microcast- $X$ microstructure exhibits a cellular type of structure. Basically, the process of Mierocast-X involves casting molten metal having low pouring temperature within about $10{ }^{\circ} \mathrm{C}$ of the melting point into a heated mould. During pouring, turbulence in the molten alloys increases their surface-to-volume ratio and, in turn, the heat-extraction rate. The closely controlled, low pouring temperature and high heatextraction rate are primarily responsible for the cellular, forging- 
like microstructure. At the same time, Air Research Casting Company [9] developed a kind of fine grain casting process (FGP). The process was established to use low pouring temperature (melting point $+22^{\circ} \mathrm{C}$ ), low melt superheat temperature, low mould preheating temperature $\left(1100^{\circ} \mathrm{C}\right)$ and local chills. For the IN 713 LC and MAR-M 247 alloy, grain size in the range of ASTM 1-2 (0.25-0.18 mm) was obtained. The similar results were obtained for In-713LC alloy recently [10]. Like FGP, Microcast-X process also reduces molten-metal fluidity, and has less ability to fill thin sections. Furthermore, the dispread of microporosities within castings due to low poring temperature must be eliminated by IHPing process, which increases production costs.

An alternative method of refinement of cast structure is nucleation promoting and growth hindering additions before pouring, or inoculation, which is more effective for grain refinement. The criteria that a good inoculant must process to perform as a stable substance for heterogeneous nucleation, including stability in the melt, be finely dispersed, have similar density to the melt and grow epitaxially with the alloy to be solidified. These principles have been used successfully to refine a considerable range of alloys either by deliberate additions to the melt or by coating the interior surface of investment mould [11-14]. Unlike most of the nonferrous alloys, grain refinement of superalloys during cast process is more difficult due to their complicated composition, multi-phases, high melting point and melted in vacuum condition.

Since 1980's, investigations on grain refinement by chemical method have been performed by researchers. Although additions of boron [15], particles of metallic oxides [16], refractory carbides and nitrides [17] could refine grains, they were not used in the industrial scale due to inclusion or lowering the incipient melting temperature of the alloys.

Although it has been considered that the inoculation of the melt is not often used with superalloys due to their high inclusion sensitivity, some successful refinement methods are still related with these methods [18]. The key to the argument is how to select the proper inoculants which have high effectiveness to promote nucleation and do not produce the inclusion.

\section{Effect of Grain Size on Mechanical Properties of Superalloys}

Finer grain generally improves tensile, fatigue and creep properties, but decreases the stress rupture lives at low to intermediate temperatures (from room temperature to $760^{\circ} \mathrm{C}$ ) $[10$, $19,20]$. Because cyclic fatigue performance today tends to dominate superalloy component life for both wrought and cast products, the following analysis is focus on this property. The results from different researchers are often not identical. Some results show that finer grains increase in low cycle fatigue life of 2 to 4 times and in high-cycle fatigue life of 5 to 14 times $[8,9,15]$, others indicate that they are quite limited in improving fatigue properties under almost same test conditions [20]. Whereas one point is in common: the major advantage of finer grained materials is a reduced scatter in the fatigue properties $[7,9,21]$. This relates to the modulus values of the alloys. The finer grained materials have higher and more consistent modulus than conventionally cast alloys, reflecting the superior isotropic behavior of former and implying reduced scatter and higher statistical minimum properties [7,9].

Although extensive work was done on the mechanical properties on fine-grained superalloys, the results were obtained mainly from the specimens prepared by thermal or mechanical methods. No research was reported by chemical methods.

In the present study, two ternary intermetallic compounds Co-Fe$\mathrm{Nb}$ and $\mathrm{Cr}-\mathrm{Mo}-\mathrm{Nb}$ have been chosen as inoculants to investigate their effects on the grain structures of cast superalloy K4169 under various melting and casting conditions. Tensile properties and low cycle fatigue properties were compared for both conventional and fine grained test bars.

\section{Materials and Experimental Procedures}

\section{Preparation of refiners}

The principal requirements for good refiners are that the refiner particles must be stable in the melt, be finely dispersed, be similar in density to the melt, and be growing epitaxially with the metal to be solidified. Meanwhile, their constituent elements are also the elements presented in the superalloy, which means their addition do not pose any harmful influence on the composition of the alloy.

According to the above mentioned principles, a serious grain refiners composed mainly of high melting intermetallic compounds was developed. The button ingots of refiners were prepared by melting an appropriate proportion of the constituents in a vacuum arc melting furnace in an argon atmosphere. They were ground into powders before being added into the alloy melt. The physical and crystallographic properties of refiners are listed in Table I.

Table I Physical and Crystallographic properties of refiners

\begin{tabular}{|c|c|c|c|}
\hline Refiner & Crystal structure & Density $\left(\mathrm{g} / \mathrm{cm}^{3}\right)$ & composition \\
\hline B1 & $\left(\mathrm{MgZn}_{2}\right) \mathrm{hp} 12$ & 8.8 & Co-Fe-Nb \\
\hline B2 & $\left(\mathrm{MgZn}_{2}\right) \mathrm{hp} 12$ & 8.1 & Cr-Fe-Nb \\
\hline
\end{tabular}

\section{$\underline{\text { Superalloy K4169 }}$}

A Fe-Ni based superalloy K4169 was used in this work. It has the following chemical composition (wt \%): $0.05 \mathrm{C}, 0.01 \mathrm{Co}, 52 \mathrm{Ni}$, $3.05 \mathrm{Mo}, 5.3 \mathrm{Nb}, 18.4 \mathrm{Cr}, 0.55 \mathrm{Al}, 1.05 \mathrm{Ti}$ and rest Fe. Its melting and solidification properties were determined by differential thermal analysis (DTA). The equilibrium liquidus and solidus of 1339 and $1254{ }^{\circ} \mathrm{C}$ were obtained respectively.

\section{Melting and Casting}

A ZG 200 type vacuum melting and casting unit, consisting of an induction furnace and a mould preheating furnace which were installed within a stainless vessel connected to vacuum pumps, was used to cast conventional and fine-grained ingots. The melt was firstly superheated up to a predetermined superheating temperature for 2-3 minutes and then cooled down to the pouring temperature. Then, for conventional cast process, the melt was poured. However, for chemical grain refinement, mixed refiner was added into the melt according to the chosen process parameters. After that, an appropriate stirring was needed in order for refiner particles to be dispersed in the melt uniformly. The melt was subsequently poured into metallographic samples for inspecting cast structure or test bars for investigating mechanical properties. The ceramic mould preheating temperature was kept at $900{ }^{\circ} \mathrm{C}$ in all cases. 


\section{Macro- and Micro-Structure Analysis}

The alloy ingots were sectioned along the transverse cross-section and samples were ground, polished and subsequently chemically etched with a solution consisting of $15 \mathrm{~g} \mathrm{CuSO}_{4}, 3.5 \mathrm{ml} \mathrm{H}_{2} \mathrm{SO}_{4}$ and $50 \mathrm{ml} \mathrm{HC1}$ to expose grain structures. The average equiaxed grain size and equiaxed fraction at transverse cross-section were determined by a standard quantitative metallographic technique by the line intercept method [22]. The grain size was also estimated with reference to the ASTM standard [23]. The distribution of the alloying elements was determined with a 733 type electron microprobe. For observing microporosity, the samples need to be polished but need not to be etched.

\section{Mechanical Property Tests}

The test bars for mechanical property test were processed into property samples with reference to Chinese National Standard GB 6397-860. Tensile properties at room temperature and $700^{\circ} \mathrm{C}$ were tested with a WJ-10B mechanical universal strength tester and a ZDM-5 tensile tester, respectively,

The fatigue test samples were prepared with $6 \mathrm{~mm}$ in diameter and the fatigue tests were carried out with a $100 \mathrm{kN}$ MAYES mechanical fatigue equipment at room temperature in static air under whole strain control pull-press loading in all re-direction axis at namely strain amplitude $\pm 0.3-0.6 \%$, with triangle wave at strain ratio $\mathrm{R}=-1$ and loading rate $1 \times 10^{-4} \mathrm{~mm} / \mathrm{sec}$.

\section{Experimental Results}

Grain Structure

Table II illustrates the experimental scheme and processing parameters, together with characteristic parameters of grain structures under various refining processing. The corresponding grain structures are shown in Figure. 1. It can be seen that lowering the pouring temperature and adding refiner to the melt can reduce grain size (D) and improve equiaxed fraction at traverse cross-section $(\mathrm{P})$. In addition, the grain size increases and proportion of equiaxed grains reduces with increasing the superheating temperature $T_{\mathrm{H}}$. It must be noticed that finer grains (less than $0.2 \mathrm{~mm}$ ) can be achieved both by addition of refiners and by lowering pouring temperature without melt superheat, as seen in sample 1, 3 and 6 in Table I. Particularly, fine grains were obtained at conventional melting and casting conditions, see sample 8 in Table I.

Table II Grain Structure Features under Various Casting Conditions

\begin{tabular}{|c|c|c|c|c|c|c|c|c|}
\hline Sample No. & Refiner addition & $\mathrm{T}_{\mathrm{H}},{ }^{\circ} \mathrm{C}$ & $\mathrm{T}_{\mathrm{P}},{ }^{\circ} \mathrm{C}$ & $\mathrm{D}, \mathrm{mm}$ & $\mathrm{ASTM}$ grade & $\mathrm{P}, \%$ & $\mathrm{~L}_{\text {axis }}$ & SDAS, $\mu \mathrm{m}$ \\
\hline 1 & No & & 1360 & 0.093 & 4.0 & 100 & & 55 \\
\hline 2 & No & & 1380 & 0.602 & $\mathrm{M} 12$ & 92 & & 60 \\
\hline 3 & Yes & 1550 & 1380 & 0.075 & 4.5 & 100 & & \\
\hline 4 & No & & 1400 & 2.25 & M8 & 56 & 135 & 66 \\
\hline 5 & Yes & 1550 & 1400 & 0.202 & 1.7 & 96 & & 61 \\
\hline 6 & Yes & & 1400 & 0.166 & 3.2 & 99 & & \\
\hline 7 & No & & 1420 & 3.84 & M6.5 & 53 & 148 & 81 \\
\hline 8 & Yes & 1550 & 1420 & 0.989 & M10.5 & 90 & 104 & 81 \\
\hline
\end{tabular}

Note: $\mathrm{T}_{\mathrm{H}}$ : Melt homogeneous treatment temperature, $\mathrm{T}_{\mathrm{P}}$ : Melt pouring temperature, $\mathrm{P}$ : Proportion of equiaxed grains at transverse section, $L_{a x i s}$ : Average principle length of primary dendrite; SDAS: Secondary dendrite arm spacing
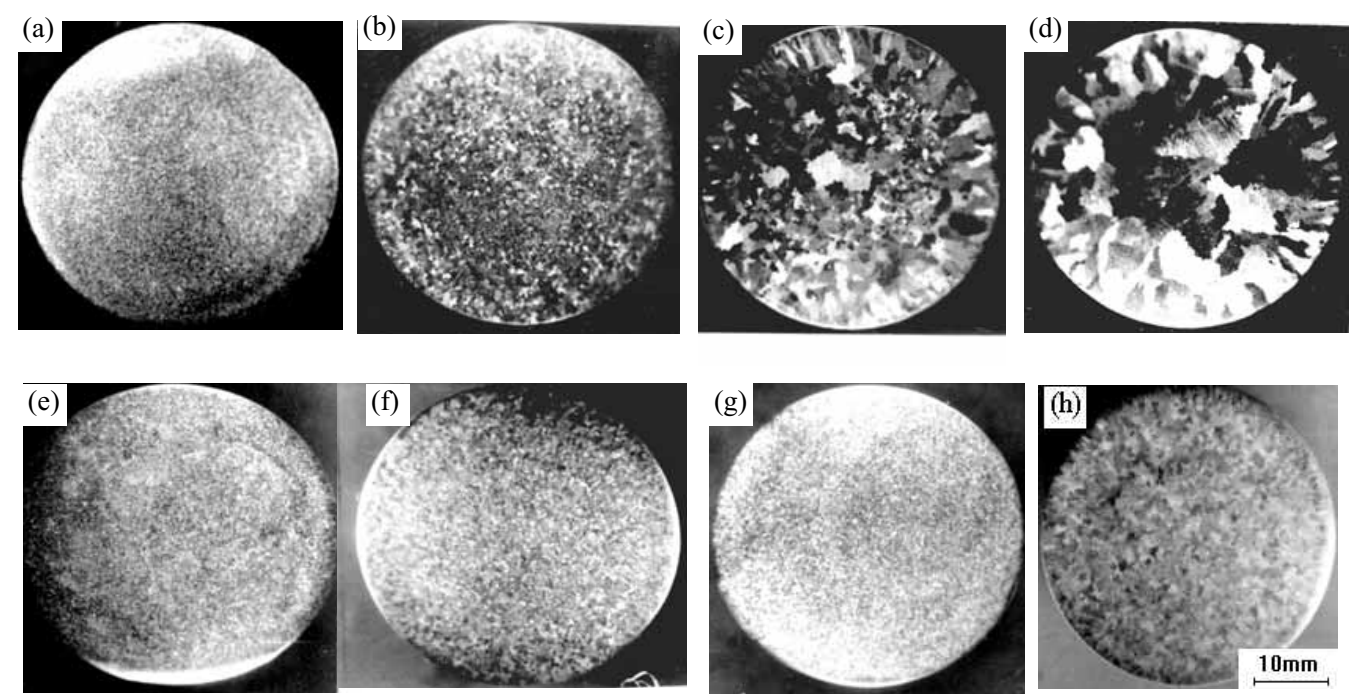

Figure 1 Grain structures of cylindrical ingots obtained under various refining processing

(a) (h) correspond to specimen No. 1, 2, 4, 7, 3, 5, 6 and 8, respectively 


\section{Dendrite Structure}

Lowering pouring temperature and addition of refiner not only reduce the grain size, but also change the morphologies of dendrites. As shown in Figure2, developed side branches were observed at higher pouring temperatures and without additions. In contrast, dendrites tend to granulate at lower pouring temperature and with refiner additions. In order to describe dendrite morphologies quantitatively, we use the length of the average primary dendrite axes $\left(\mathrm{L}_{\text {axes }}\right)$ and the secondary dendrite arm spacing (SDAS) to characterize the morphological features of dendrites. The grains of samples No. 3 and No. 6 are almost granular so that it is impossible to test their $\mathrm{L}_{\text {axe }}$ and SDAS.

It can be seen from Table II that the $\mathrm{L}_{\text {axe }}$ decreases with the refinement of the grains. Whereas the value of SDAS keeps almost the same at the same pouring temperature despite that grain has been refined. In such a case, a great number of grains nucleate simultaneously and grow competitively at a velocity determined by their local temperature, which makes the region of constitutional supercooling decrease. These grains soon impinge on one another and prevent further growth. As a result, the $1_{\text {axe }}$ decreases after grains in the castings were refined.
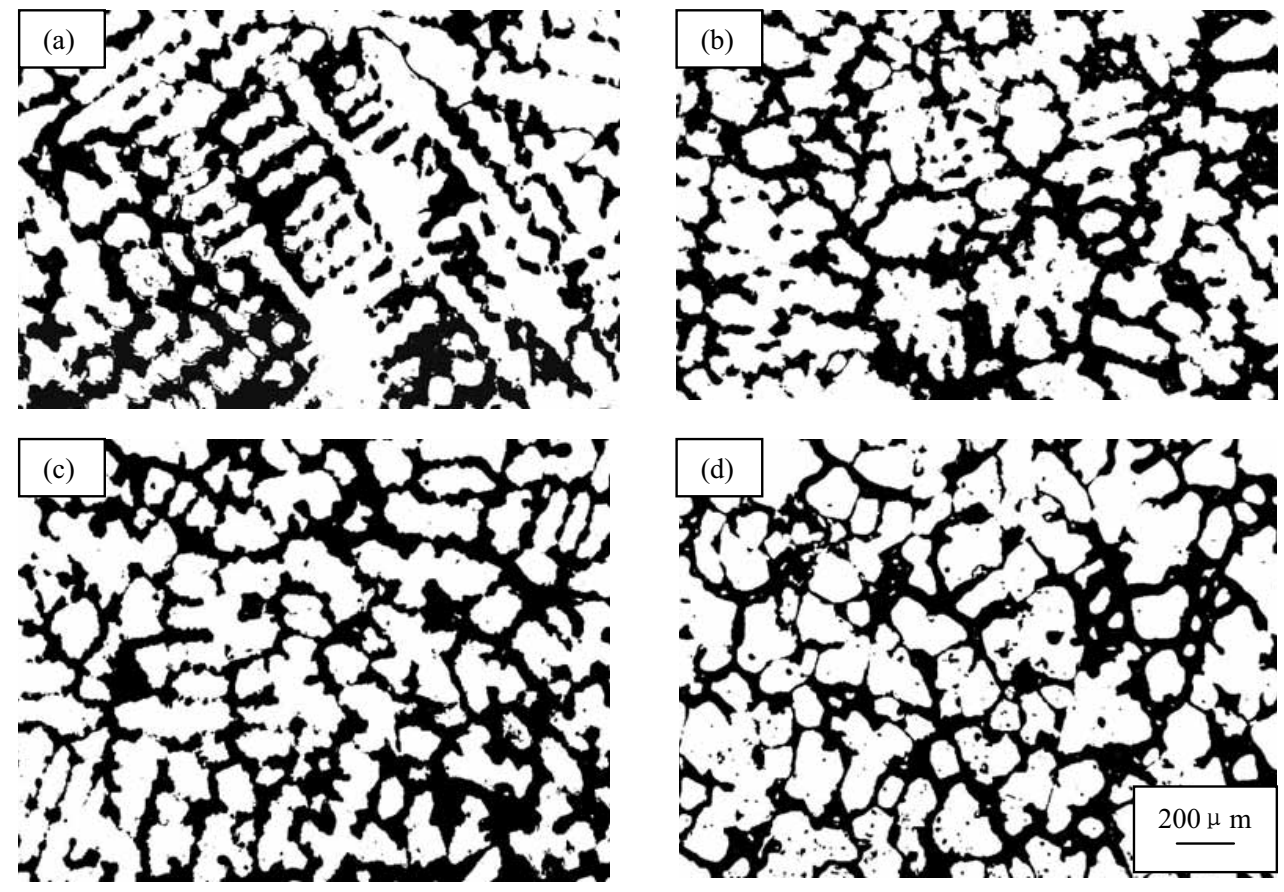

Figure2 Microscopic grain structure of cylinder ingots under various refining processing

(a) Sample No.7, pouring at $1420^{\circ} \mathrm{C}$ without addition

(b) Sample No.8, pouring at $1420^{\circ} \mathrm{C}$ with addition

(c) Sample No.4, pouring at $1400^{\circ} \mathrm{C}$ without addition

(d) Sample No.6, pouring at $1400^{\circ} \mathrm{C}$ with addition

Interdendritic Segregation

The segregation ratio is defined as the maximum concentration in interdendrite areas over the minimum concentration in the center of dendrite trunk. Figure 3 illustrates the segregation ratio of elements $\mathrm{Fe}, \mathrm{Cr}, \mathrm{Mo}, \mathrm{Nb}$ and $\mathrm{Ti}$ of samples No. 4, 5, 6, 7 and 8 determined by microprobe. It can be concluded that $\mathrm{Mo}, \mathrm{Nb}$ and $\mathrm{Ti}$ are positive segregation elements, $\mathrm{Fe}$ and $\mathrm{Cr}$ are negative ones. The results also indicate that segregation alleviates after grain refinement. It is suggested that spatial scope for the growth of dendrites diminishes along with grain refinement, resulting in the reducing of segregation in distance and amplitude, which is the most important reason for the lessening of segregation. Meanwhile, it is known from the above observation on the morphologies of grains that the number of granular grains increases after grain refinement. Thus, the elimination of dendrite structures makes it inconvenient for elements to be rejected in interdendritic areas, which helps to reduce segregation.

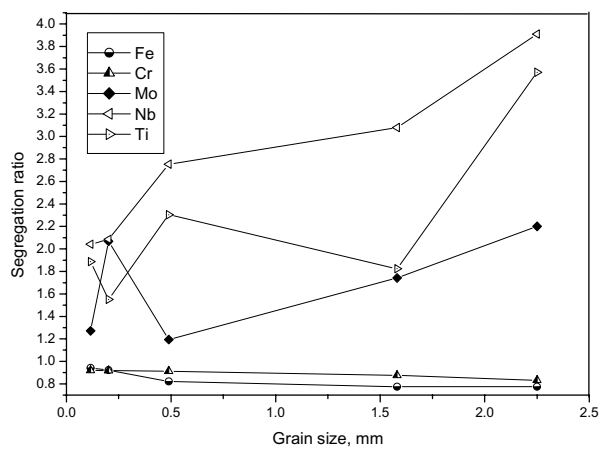

Figure3 Variation of segregation ratio of alloying elements with grain size 


\section{Microporosity}

Superalloy K4169 is subject to forming microporosity due to wide freezing range. Figure 4 illustrates the effect of pouring temperature and refiner additions on microporosity. It can be found that there is less microporosity at higher pouring temperature, or with addition of refiners. By comparing Figure 4 (a) and (c), we can see that microporosities reduce in great extent although grain size is almost the same, implying that both fine grain and less microporosities can be achieved through higher pouring temperature together with addition of refiners. The results also reveal two important phenomena: Firstly, the liquid within interdendrite has a better feeding ability at higher pouring temperature. Secondly, the granular grain without having developed branches can reduce the resistance to the liquid flow in interdendritic areas.

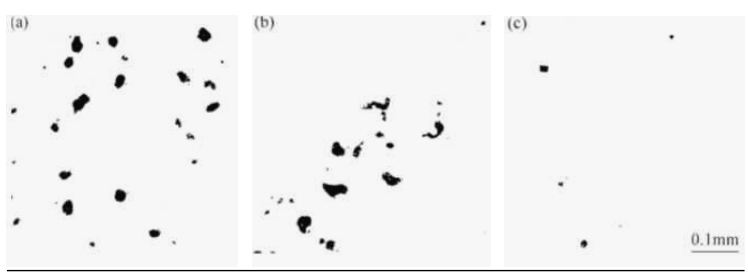

Figure 4 Microporosities under different pouring temperature and refiner additions

(a) pouring at $1360^{\circ} \mathrm{C}$ without addition, grain size $0.093 \mathrm{~mm}$

(b) pouring at $1400^{\circ} \mathrm{C}$ without addition, grain size $2.25 \mathrm{~mm}$

(c) pouring at $1400^{\circ} \mathrm{C}$ with addition, grain size $0.116 \mathrm{~mm}$

\section{Tensile Properties}

Table III shows the data of tensile properties at room temperature and at $700^{\circ} \mathrm{C}$. When the grain size is between 0.20 and $2.25 \mathrm{~mm}$, the yield strength, ultimate strength, elongation and reduction of area are increasing marginally along with the progress of grain refinement at room temperature. At $700^{\circ} \mathrm{C}$, the situations are the same for both strength properties. In terms of elongation and reduction of area, the behavior is different. When grains are refined, the value of them drops.

Table III Tensile Properties for different grain size

\begin{tabular}{|c|c|c|c|c|c|c|}
\hline Process & Average & \multicolumn{5}{|c|}{ Tensile properties } \\
\cline { 3 - 7 } & $\begin{array}{c}\text { grain } \\
\text { size }\end{array}$ & $\begin{array}{c}\text { Test } \\
\text { temp. }\end{array}$ & $\begin{array}{c}\sigma_{\mathrm{b}} \\
(\mathrm{MPa})\end{array}$ & $\begin{array}{c}\sigma_{0.2} \\
(\mathrm{MPa})\end{array}$ & $\delta(\%)$ & $\varphi(\%)$ \\
\hline Conventional & 2.25 & $\mathrm{RT}$ & 751.3 & 592.7 & 12.3 & 16.0 \\
\cline { 3 - 7 } process & $\mathrm{mm}$ & $700^{\circ} \mathrm{C}$ & 638.3 & 502.7 & 12.1 & 16.4 \\
\hline Fine grain & 0.20 & $\mathrm{RT}$ & 936.7 & 650 & 16.1 & 20.3 \\
\cline { 3 - 7 } process & $\mathrm{mm}$ & $700^{\circ} \mathrm{C}$ & 733.3 & 610 & 8.17 & 13.0 \\
\hline Note: RT: Room temperature, $\sigma_{\mathrm{b}}:$ Ultimate strength, $\sigma_{0.2}:$ Yield \\
strength, $\delta:$ Coefficient of elongation, $\varphi:$ Reduction of area \\
\hline
\end{tabular}

\section{Low Cycle Fatigue Properties}

Figure5 illustrates the low cyclic fatigue lives at various strain amplitudes. It can be seen that finer grain improves the LCF lives significantly at room temperature. Especially, the lower the strain amplitude, the larger the difference of fatigue life is. Fatigue life of fined grain sample increases from about $20 \%$ at $\Delta \varepsilon_{\mathrm{t}}=0.2 \%$ to about $100 \%$ at $\Delta \varepsilon_{\mathrm{t}}=0.6 \%$.

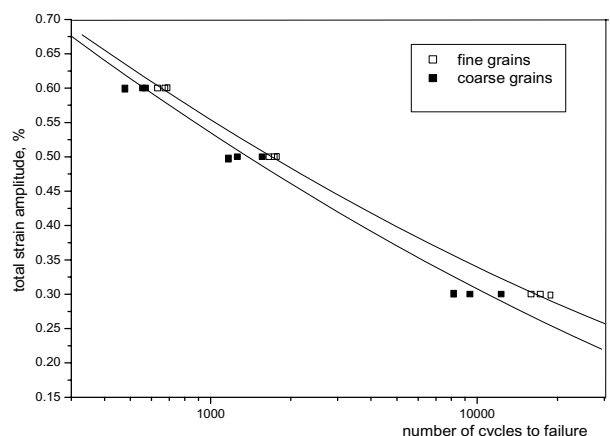

Figure 5 Fatigue lives at room temperature

In addition, the dispersion degree of LCF data of fined grain samples is diminished. Table IV shows the variance logarithm of fatigue lives. It can be seen that the values of fatigue life for fine grain samples are higher than those for coarse grain samples at all strain levels.

Table IV The Variance Logarithm of Fatigue Lives Data $\left(\operatorname{lnS}_{\mathrm{n}}{ }^{*}\right)$

\begin{tabular}{|c|c|c|c|}
\hline$\varepsilon_{T} \%$ & $0.3 \%$ & $0.5 \%$ & $0.6 \%$ \\
\hline Coarse grains & 10.29 & 7.08 & 7.15 \\
\hline Refined grains & 8.21 & 4.92 & 4.27 \\
\hline
\end{tabular}

\section{Discussion}

\section{Grain Refinement Mechanism}

Generally, the effectiveness of a refiner is related to the lattice disregistry between it and the nucleated phase. The less the lattice disregistry, the more effective the refiner in promoting nucleation is [24]. In this study, refiners B1 and B2 have the same crystal structure type and low lattice disregistry, less than $6 \%$ between the $\gamma$ matrix of the alloy. We can calculate the lattice disregistry $\delta$ between refiners and the matrix for specific crystal planes according to the calculation model of lattice disregistry proposed by Bramfitt [25]. The results show that the values of $\delta$ are $5.03 \%$ and $3.77 \%$ between (0001) planes of refiners B1 and B2 and (111) planes of $\gamma$ matrix, respectively. In addition, the values of $\delta$ between $(10 \overline{1} 0)$ planes of refiners $\mathrm{B} 1$ and $\mathrm{B} 2$ are $4.93 \%$ and $5.36 \%$ between (011) planes of $\gamma$ matrix, respectively. Figure 6 shows the lattice compatibility between two refiners and $\gamma$ matrix in some low-index planes. Where, subscripts $s$ and $n$ represent substrate and nuclei, and $a$ and $c$ are the lattice distances. It can be seen that there exits a good lattice matching between the substrate provided by the refiners and the nuclei of $\gamma$ matrix of the alloy. In this case, the refiners can act as the nucleation substrata of $\gamma$ matrix and allow its expitaxial growth with the refiners. The presence of a great number of active refiner particles in the melt would cause enormous heterogeneous nucleation of several crystallites, which would impinge on one another and restrict further growth. Hence, grain structure can be refined by the addition of refiner. 


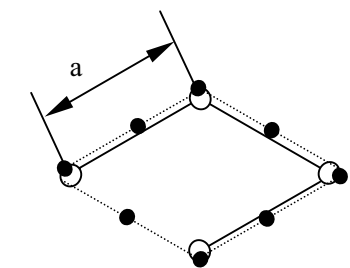

(a) $(0001) \mathrm{s} / /(111) \mathrm{n}$

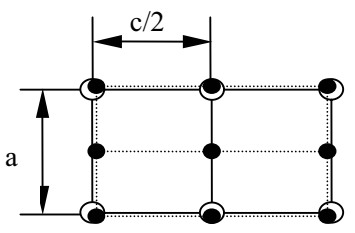

(b) $(10 \overline{1} 0) \mathrm{s} / /(011) \mathrm{n}$



- Matrix atoms

Figure 6 Schematic view of lattice matching between inoculants and $\gamma$ matrix

\section{Mechanism of Increasing in the Proportion of Equiaxed Grains}

It can be seen from Table II and Figure1 that lowering the pouring temperature or adding refiner to the melt make the equiaxed fraction increase along with the grain refinement. It is known that the condition that equiaxed grains appear ahead of the columnar front can be expressed in the following equation [26-27],

$G<\eta n^{\frac{1}{3}}\left[1-\left(\frac{\Delta T_{N}}{\Delta T_{C}}\right)^{3}\right]\left[-8 \Gamma m\left(1-k_{0}\right) \frac{C_{0} V}{D}\right]^{\frac{1}{2}}$

where $G$ is the temperature gradient $(\mathrm{K} / \mathrm{m}), \eta$ a columnar to equiaxed transition coefficient relative to the alloy, $n$ the number of sites per cubic meter $\left(\mathrm{m}^{-3}\right), \Delta T_{N}$ the undercooling at the heterogeneous nucleation temperature $(\mathrm{K}), \Delta T_{C}$ an undercooling equal to that of the columnar growth front $(\mathrm{K}), \Gamma$ Gibbs-Thomson coefficient (m.K), $m$ the liquidus slope(K/wt.\%), $k_{o}$ the distribution coefficient, and $D$ the liquid diffusion parameter $\left(\mathrm{m}^{2} / \mathrm{s}\right)$. There exists the relation $\Delta T_{C} \propto\left(V C_{0}\right)^{\frac{1}{2}}$, with $V$ the growth velocity $(\mathrm{m} / \mathrm{s})$, and $C_{0}$ alloy composition (wt. \%). Equation (1) reveals that lowering $G$ and increasing in $n, V$, and $m C_{0}\left(1-k_{0}\right)$ have an advantageous for the formation of equiaxed grains. Low pouring temperature $T_{p}$ reduces temperature gradient $G$, which helps to increase the constitutional undercooling. In addition, low $T_{p}$ could increase cooling rate, resulting in the increase of melt supercooling and $V$. That is to say, low $T_{p}$ can reduce the left-hand side of equation (1) and increase the righthand side, contributing to the formation of equiaxed grain zone.

From the well-known criterion of constitutional undercooling $\frac{G}{V} \geq \frac{m C_{0}\left(1-k_{0}\right)}{D k_{0}}$

we can see that lowering in $G$ and increasing in $V$ and $-m C_{0}\left(1-k_{0}\right)$ are helpful for forming equiaxed grains. However, the effect of $n$ is not considered. The addition of refiner results in an increase in $n$, the number of equiaxed nuclei per cubic meter, leads to the increase of the right-hand side of equation (1). As a result, it is beneficial for the forming of equiaxed grain zone. Additionally, refiner particles dispersed uniformly in the melt produce two effects: (1) they cause a large quantity of equiaxed grains to form and release a great amount of latent heat which prohibits the crystal growth. (2) The formation and growth of many equiaxed grains impede the growth of columnar grains.

\section{Tensile Properties under $700^{\circ} \mathrm{C}$}

Elevation of testing temperature has obvious effects on tensile properties of materials. Strength data of fined grain structures were still higher than that of coarse grain structures at $700^{\circ} \mathrm{C}$, indicating equal strength temperature $\left(T_{\text {equ }}\right)$ was higher than $700^{\circ} \mathrm{C}$ for tensile deformation of alloy $\mathrm{K} 4169$. The improvement of tensile strength can be attributed to the having of more grain boundaries of refined structures and the small block-type $M C$ carbides, which can impede crack propagation, thus improving fracture strength. But elongation and reduction in area decrease at $700^{\circ} \mathrm{C}$. which can be explained by changes of fracture toughness according to Tetelman's fracture toughness formulation [28]

$$
K_{I C}=2.9 \sigma_{0.2}\left[\exp \left(\sigma_{b} / \sigma_{0.2}-1\right)-1\right]^{1 / 2} \rho^{1 / 2}
$$

Where $\rho$ is the radius of end of crack. Obviously, the larger the value of $\left(\sigma_{b} / \sigma_{0.2}\right)$, the larger of fracture toughness is and the smaller the brittle of the grain structure is. From the experimental results in Table III, the values of $\left(\sigma_{b} / \sigma_{0.2}\right)$ of refined structure vary from 1.45 to 1.20 as temperature changes from room temperature to $700^{\circ} \mathrm{C}$. That is refined structure becomes more brittle at elevated temperature. While the values of $\left(\sigma_{b} / \sigma_{0.2}\right)$ of coarse grain structure has no change (from 1.27 to 1.27). Its fracture toughness $K_{I c}$ changes little and keeps larger value, so that refined structure produces crack propagation quickly and its deformation amount is less. That is why elongation and reduction of area of refined structure were less than coarse grain structure.

Another explanation of the facts above is that the precipitates at grain boundaries have lower capability to resist oxidation than $\gamma$ matrix at $700^{\circ} \mathrm{C}$, resulting in crack propagation rate to be faster at grain boundaries and crack to occur at surfaces of grain boundaries. As a result, the ductility level of fine-grained sample with much more grain boundaries is reduced.

\section{Conclusions}

(1) Intermetallic compound grain refiners for superalloys were developed, which have high melting point, good dispersion in the alloy melt, reasonable density and less mismatch with the matrix and do not bring inclusions into to the alloy. Therefore, the refiner is ideal for the grain refinement of superalloys.

(2) While adding refiner to the melt, a uniform and fine grains of superalloys can be realized under conventional melting and casting conditions. The average size of equiaxed grains could be refined to the order of ASTM 3.2. Equiaxed fraction at transverse cross-section could be improved from 56\% to $99 \%$.

(3) The segregation ratios of main elements such as $\mathrm{Fe}, \mathrm{Cr}, \mathrm{Nb}$, $\mathrm{Mo}$ and $\mathrm{Ti}$ are close to 1 progressively with the decrease in grain size, which is beneficial for the improvement of mechanical properties. 
(4) The morphology of grains is transformed from dendrite in conventional castings to granulation in fine-grained castings.

(5) Low pouring temperature reduces temperature gradient, increases cooling rate, melt supercooling and nucleation undercooling, resulting in grain refinement. Refiner particles of good lattice compatibility with $\gamma$ matrix act as substrata of $\gamma$ matrix, thereby causing grain refinement.

(6) All tensile properties for fine grained samples are more superior to those of the coarse grained ones at room temperature. At $700^{\circ} \mathrm{C}$, the situations are the same for both strength properties, but the values of elongation and reduction of area drops for refined grains. This is caused by the different value of $\sigma_{b} / \sigma_{0.2}$ at various temperatures.

(7) Finer grain improves the LCF lives significantly at room temperature, ranging from $20 \%$ to $100 \%$, according to the strain amplitude. In addition, the dispersion degree of LCF data of fined grain samples is diminished.

\section{Acknowledgments}

This work was supported by State Key Fundamental Research Plan of China under grant No.G2000067202. The authors would like to thank Dr.Yipng Guo, Dr. Wei Liu, Dr. Jinagbang Zheng for participating in partial experimental and theoretical work.

\section{References}

1. C. T. Sims, "Superalloys: Genesis and Character," Superalloys II- High Temperature Materials for Aerospace and Industrial Power, eds. C.T Sims, N. S. Stoloff, and W.C. Hagel, (New York, John Wiley \& Sons, 1987), 3.

2. G.K. Bouse, and J. R. Mihalisin, "Metallurgy of Investment Cast Superalloy Components," Superalloys, Supercomposites and Superceramics, eds. J. K. Tien, and T. Caulfied, (Boston, Academic Press, 1989), 99.

3. J. K. Tien, J. C. Borofka, and M. E. Casey, "Precision cast vs Wrought Superalloys," J. of Metals, 38 (12) (1986), 13-17

4. M. McLean, "Investment Casting-Developments in Microstructural Control and Mechanical Performance," Materials Science and Technology, 4, March 1988, 205-217

5. J. R. Brinegar, L. F. Norris, and L. Rosenberg, "Microcast-X Fine Grain Casting - A Progress Report," Superalloy 1984, eds. M. Gell, C S. Kortovich, R. H. Bricknell, W. B. Kent, and J. F. Radavich, (The Metallurgical Society of AIME, 1984), 23-32.

6. D. E. Macha, G. R. Cole, and J. A. Butzer, "Fine Grain, Investment- Cast Integral Turbine Wheels," Grain Refinement in Casting and Welds, eds. G... J. Abbaschian, and S. A. David, (The Metallurgical Society of AIME, 1983), 197-219.

7. B. A. Ewing, K. A. Green, " Polycrystalline Grain Controlled Casting for Rotating Compressor and Turbine Components," Superalloy 1984, eds. M. Gell, C. S. Kortovich, R. H. Bricknell, W. B. Kent, and J. F. Radavich, (The Metallurgical Society of AIME,1984), 33-42.
8. J. M Lane, "Investment Cast Superalloys Challenge Wrought Materials," Advanced Materials \& Processes. 138 (4) 1990, 107108.

9. M. Woulds, and H. Benson, "Development of a Conventional Fine Grain Casting Process," Superalloy 1984, eds. M. Gell, C. S. Kortovich, R. H. Bricknell, W. B. Kent, and J. F. Radavich, (The Metallurgical Society of AIME,1984), 3-12.

10. C. N. Wei, H. Y. Bor, C. Y. Ma, and T. S. Lee, A Study of In 713LC Superalloy grain Refinement Effects on Microstructure and Tensile Properties," Materials Chemistry and Physics, 80 (2003), 89-93.

11. B. S. Murty, S. A. Kori, and M. Chakraborty, "Grain Refinement of Aluminium and its Alloys by Heterogenoous Nucleation and Alloying," International Materials Review, 47 (1) (2002), 3-47.

12. J. Fang, and B. Yu, "Investment of Surface Grain Refinement for Superalloy Castings," High Temperature Alloys for Gas Turbines 1982, eds. R. Brunetaud et al., (D. Reidel Pub., 1982), 987-997.

13. E. Chang, B. Tseng. J. C. Chou, and V. Yin, "Processing, Structure and Mechanical Property of Investment Cast In 713C Superalloy," AFS Transaction, 88-124, 47-54.

14. K. H. Kloos, K. Stein, and S. Keiser, "Gefügeausbildung und Machanishe Eigenschafen der Nikelbasislegierung In 738LC, ” Metall, 38 (1984), 740-747

15. A. F. Denzine, T. A. Kolakowski, and J. F. Wallance, "Grain Refinement of Cast Nickel-Base Superalloys and its Effect on Properties," Proc. AGARD Conf. on Advanced Casting Technology, (AGARD Conf. Proc., No.325, 1982).

16. J. P. Dennison, "Grain Refinement by the Introduction to the Melt of Oxide Particles Pre-dispersed in Melt Strip," Grain Refinement in Casting and Welds, eds. G... J. Abbaschian, and S. A David, (The Metallurgical Society of AIME, 1983), 139-149.

17. B. L. Zhen, L. Liu, Z. Y. Yong, A. Banerji, W. Reif, "Grain Refinement of Superalloy In 738LC," Metall, 48 (2) (1994), 118122.

18. W. J. Molloy, "Investment Cast superalloys: A Good Investment," Advanced Materials \& Processes, 138 (4) (1990), 23-29.

19. W. R. Freeman Jr, "Investment Casting," Superalloys - II High Temperature Materials for Aerospace and Industrial Power, eds. C. T. Sims et al., (New York, Jone Wily \& Sons, 1987), 411439

20. M. Nazmy, B. Weiss, and R. Stickler, "The Effect of Advanced Fine Grain Casting Technology on Static and Cyclic Properties of In 713LC," High Temperature Materials for Power Engineering 1990 II, (The Netherlands, Kluwer Academic Publishers, 1990), 1397-1404.

21. T. B. Gibbons, S. Osgergy, F. Gabrielli, and V. Lupinc, "Factors Controlling Creep Strength of Cast Ni-Cr-Base Alloys," 
Materials Science and Technology, 3 (1987), 268-274

22. E. E. Underwood, Metals Handbook Vol. 8, 8th ed., (Metals Park, OH: ASM, 1973), 37.

23. American National Standards Institute, "Standard Methods for Estimating the Average Grain Size of Metals," Annual Book of ASTM Standard, 1977, 207.

24. L. F. Mondolfo, "Grain Refinement in the Casting of NonFerrous Alloys," Grain Refinement in Casting and Welds, eds. G. J. Abbaschian, and S. A. David, (The Metallurgical Society of AIME, New York, 1983), 3-50.

25. B. L. Bramfitt, "The Effect of Carbide and Nitride Additions on Heterogeneous Nucleation Behavior of Liquid Iron," Metallurgical Transactions, 1 (1970), 1987-1993.

26. J. D. Hunt, "Steady State Columnar and Equiaxed Growth of Dendrites and Eutectic," Materials Science and Engineering, 65 (1984), 75-83.

27. D. Z. Li., et al., "Structure Simulation and Variable Optimization of Solidification Process for Nickel-Base Superalloy Blades," Foundry, 8 (1997), 1-7 (In Chinese).

28. D.E. Macha, G.R. Cole, and J.A. Butzer, "Fine Grain, Investment-Cast Integral Turbine Wheels," Grain Refinement in Casting and Welds, eds. G. J. Abbaschian, and S. A. David, (The Metallurgical Society of AIME, New York, 1983), 197-219 